\title{
Knowing public services: Cross-sector intermediaries and algorithmic governance in public sector reform
}

\section{Ben Williamson}

ben.williamson@stir.ac.uk

Pre-publication version accepted in Public Policy $\mathcal{E}$ Administration 


\title{
Knowing public services: Cross-sector intermediaries and algorithmic governance in public sector reform
}

\begin{abstract}
Discourses of public sector reform in the UK have been shaped in recent years by the participation of new kinds of hybrid cross-sector intermediaries such as think tanks, social enterprises and other third sector organisations. This article provides a documentary analysis of Demos, NESTA and the Innovation Unit as intermediary organisations in public sector reform, exploring their promotion of modes of digital governance and their mobilisation of new software technologies as models for new kinds of governing practices. These intermediary organisations are generating a model of knowing public services that operates through collecting and analysing big data, consisting of personal information and behavioural data on individual service users, in order to co-produce personalised services. Their objective is a new style of political governance based on human-computer interaction and machine learning techniques in which citizens are to be governed as co-producers of personalised services interacting with the algorithms of database software.
\end{abstract}

\section{Keywords}

big data, co-production, governance, intermediaries, personalisation, policy labs, public service reform, think tanks

Ideas about the reform and governing of public services in the UK have been partly shaped in recent years by emerging cross-sectoral intermediary organisations. As detailed later, these include the think tank Demos, the National Endowment for Science, Technology and the Arts (NESTA), and the not-for-profit Innovation Unit. They are seeking to reconfigure public services to meet individual citizens' specific personal needs, a process of "co-producing" and "personalising" public services (Meijer 2012) that requires knowledge and information about service users to be "collated, monitored and interpreted by service providers, and even used as the basis for forecasting future needs" (Grek \& Ozga, 2010: 285). The task of personalising public services envisioned by these organisations involves the use of 
Williamson, B. 2014 forthcoming. Knowing public services: Cross sector intermediaries and algorithmic governance in public sector reform. Public Policy \& Administration.

sophisticated software and algorithms that can be used to collect and analyse "big data" on service users, consisting of personal information and individual behavioural data, in order to anticipate or even predict citizens' future lives, behaviours, and requirements. Public service users are envisaged by them as coproducers alongside database software of personalised services. All of this is part of a shift in the governance of public services to the use of new kinds of "governing knowledge" - knowledge about service users and citizens that is collected from them in order to govern them more effectively (Fenwick, Mangez \& Ozga 2014). The development of a new form of knowing public services, co-produced through personalised modes of governing and big data technologies, is a major objective of the cross-sectoral intermediaries examined in this article.

The aspiration for a more personalised and knowing public service provision in the UK public sector is examined below as a prototype of what the political scientists Margetts and Dunleavy (2013) have described as "digital-era governance" which puts "human-computer interaction" at the centre of government. Digital governance, in their account, embeds "electronic delivery at the heart of the government business model," and includes activities such as "digitizing interactions with citizens"; "new forms of automation using 'zero-touch technologies' that do not require human intervention"; and partly involves making "citizens do more, developing isocratic administration-or 'do-it-yourself' government" (Margetts \& Dunleavy 2013: 6). NESTA, Demos and the Innovation Unit have been imagining and promoting (and in some cases actively prototyping) particular approaches to digital governance based on human-computer interaction in UK public services. The article seeks to show how documents produced by these organisations have sought to reimagine citizens as participative DIY co-producers of "personalised" public services, whose interaction with providers is imagined to be highly mediated by sophisticated computer technologies with the capacity to "know" citizens by collecting, collating and calculating data about them in order to "anticipate individuals' future lives" (Kitchin \& Dodge 2011: 86). These organisations envision a reformed public sector for the emerging context of "knowing capitalism" (Thrift, 2005) in which database software and algorithmic data processing techniques are mobilised by public, private and third sector organisations alike to gather the knowledge required to govern individuals. Based on anticipatory software algorithms that are increasingly capable of predicting individuals' attributes and behaviours through "big data," sometimes called "machine learning," "data mining" or "predictive analytics" (Mackenzie 2013), these knowing technologies are part of an imagined shift towards more automated, anticipatory and algorithmic forms of digital governance in the public sector.

To be clear, the article offers an interpretation of a new model of the future of the public sector, knowing public services, that is imagined by cross-sector intermediaries as being co-produced through the DIY self-governing activities of 
Williamson, B. 2014 forthcoming. Knowing public services: Cross sector intermediaries and algorithmic governance in public sector reform. Public Policy \& Administration.

citizens and the algorithmic machine learning processes of digital database technologies in concert. Ultimately, database software and its algorithmic machine learning capacities are viewed by such organisations as technologies that can augment and even co-produce personalised services alongside service users and service providers. This is an emerging and under-examined form of humancomputer interaction in digital governance. The article has three interrelated aims. The first is to articulate the mode of cross-sectoral governance promoted by these institutions. The second aim is to explore their principal ideas about public service reform, particularly the kinds of human-computer governing practices they aspire to mobilise in order to shape the behaviour of citizens. And the third aim is to examine the kind of citizen that these organisations aspire to shape through such digitised governing practices. Before addressing these aims, some background context and methodological considerations need to be taken into account.

\section{Public service governance}

This article is based is an ongoing project to document the participation of crosssectoral organisations, think tanks and other intermediaries in public services in the UK. In particular the research seeks to interpret and explain how the UK public sector is increasingly governed by "policy networks" of relationships between public, private and cross-sectoral intermediaries which have (partially) displaced large bureaucratic regimes in a context that is "moving from a bureaucratic/professional knowledge ... of the public sector to individualised, personalised and integrated knowledge about a society" (Grek \& Ozga, 2010: 272). Throughout, the analysis mobilises conceptual resources from three overlapping fields: from political and policy studies of shifting governance; from analyses of the specific styles and techniques of governing that endeavour to govern by "acting upon the action," conduct and capacities of individuals (Rose (1999: 4); and from studies of the role of software and big data in governance.

The present article is focused on a sample of twenty-six texts produced by three intermediary organisations in the UK (or by individuals from these organisations), primarily reports, essays, pamphlets and web articles, in which a series of interrelated ideas for public service reform and governance have been articulated. The focus is on analysing these texts in order to articulate what intermediary organisations want to happen - their normative aspirations to reform and govern public services - rather than on empirically observable policy developments. The overall analysis has involved close reading and annotation of the selected texts, revealing two distinct but overlapping clusters of big ideas for public services reform. First, the promotion of much greater DIY participation in the co-production and personalisation of services (Needham 2011); and second, algorithmic techniques of data collection, calculation and machine learning that have the capacity to "see," "know," and "anticipate" citizens' lives and thus to make them amenable to 
Williamson, B. 2014 forthcoming. Knowing public services: Cross sector intermediaries and algorithmic governance in public sector reform. Public Policy \& Administration.

governing (Ruppert 2012). Co-production and personalisation, mediated and augmented by human-computer interaction and machine learning, are being embedded by these organisations at the centre of their model vision for governing the future of public services (Margetts \& Dunleavy 2013).

Debate over public service governance and reform has become increasingly pronounced in recent years, particularly under "Third Way" and "Big Society" policy banners in the UK (Alcock \& Kendall, 2011; MacMillan, 2013) but also across Europe through new approaches to the co-production, co-management and cogovernance of public services (Brandsen \& Pestoff, 2006). As Milbourne \& Cushman (2013: 488) argue, the ideal of the Big Society in UK policy discourse "rests on the notion of a consensual society where the aims of local individuals, organisations, government and other powerful actors are unproblematically in alignment." According to Painter (2013: 15), based on an analysis of UK public sector reform continuities over the last fifteen years, a "paradigmatic realignment of state, markets and civil society" is being driven through themes of open data, local accountability, Big Society, social enterprise, decentralised performance management, nudging, and network governance or even self-governance. Davies (2012: 774) argues that public policy renewal is being driven by a new "style of government" with its own distinctive governing techniques, one in which relations between the state and citizens are being reshaped, at least partly, through techniques of "big data" collection and data mining that allow patterns, trends and correlations to be identified and used as the basis for auditing, predicting, "nudging" and governing citizens' behaviour.

In this context, intermediary organisations that cut across state, markets and civil society have become increasingly significant policy actors. The emphasis in this article is on three intermediary organisations, selected because of their close interorganisational connections and, as shown below, because between them they have generated a distinctive discursive repertoire for public service reform. The research centres on texts produced by Demos, NESTA and the Innovation Unit. These three organisations are all highly promiscuous producers of documents in relation to public service reform, including printed reports and pamphlets, as well as virtual materials, websites, visualisations, diagrams and infographics, and social media such as blogs and messages on Twitter. Through the production and wide dissemination of such texts, they have introduced into public service reform a discursive repertoire of concepts such as "co-production," "personalisation," "proam power" and "radical efficiencies," paralleled with computational ideas about networked technologies, social media, big data, analytics software, and other algorithmic processes. As Demos co-founder Geoff Mulgan (2005) has argued, new models of networked "e-governance" involving civil society organisations are coevolving with new interactive web technologies, algorithmic models and open source methods. Specifically, Demos, Nesta and the Innovation Unit have 
Williamson, B. 2014 forthcoming. Knowing public services: Cross sector intermediaries and algorithmic governance in public sector reform. Public Policy \& Administration.

contributed to the ideational invention of new models of digital governance, driven by cross-sectoral intermediary organisations, in which individual citizens are to be understood and treated both as participative co-producers and as sources of data that can be analysed using machine learning algorithms in order to personalise public services.

\section{Innovation intermediaries}

What are Demos, NESTA and the Innovation Unit? This section seeks to conceptualise these organisations as particular kinds of actors with a unique organisational, intellectual and political approach to the governance of the public sector. An important place to start is with Geoff Mulgan, a co-founder of Demos, the cross-party think tank of the centre left in 1993, later a leading advisor to the New Labour government, Chief Executive of the Young Foundation, and most recently (2011- ) the Chief Executive of NESTA. Reflecting on Demos, Mulgan (2006: 151-52) suggests it had been engaging in a form of "guerilla warfare" to expand the political space: adopted an intellectually promiscuous approach to ideas, a practical "do tank" mentality, and self-consciously iconoclastic, irreverent and insurgent "shock tactics" to "change the way people think." Demos is self-consciously part of what has been termed the "radical centre" (Bentham, 2006) of think tank culture in British politics.

Practically, Demos carries out its own research and produces a huge number of reports ("pamphlets") and edited collections which it self-publishes and makes available for free under a Creative Commons open access license. While Demos is clearly in the ideas business, it must also be viewed as a material producer of particular kinds of textual and virtual products which are appealing and accessible beyond the closed confines of either political lobbying or academic publishing. Organisationally, Demos hybridises the traditional "independent" think tank (a concept explored further below), the political campaign group, and the media producer. The discursive output of Demos has been promiscuous. It has, for example, published pamphlets and collections on "networks" as "the language of our times" (McCarthy, Miller \& Skidmore 2004); “open source" technologies as models for more open forms of politics, social innovation, and public participation (Mulgan \& Steinberg 2005); and on innovative "participative," "co-produced" and "personalised" methods in public sector reform, including education, public health, and social welfare (Leadbeater, Bartlett \& Gallagher 2008).

In 2013, Demos published a twenty year anniversary booklet, entitled Twenty Years of Ideas, revisiting many of its key topics and reaffirming its influence on "the language of politics" and the "vocabulary for public service reform" (Goodhart 2013: 11). In particular, the booklet highlights the continuing commitment of Demos to listening to citizens and treating individuals' concerns as "a kind of 'data' to which policy and politicians must respond" (Goodhart 2013: 14). In its most recent publications it 
Williamson, B. 2014 forthcoming. Knowing public services: Cross sector intermediaries and algorithmic governance in public sector reform. Public Policy \& Administration.

aspires to a "postliberal future" for politics and policymaking with a "bias towards the local and the particular, in public services and in society more generally," and to "better interaction between politics and the internet/social media, to enable a higher level of digital "voice'" (Goodhart 2014: n.p.). In line with these aspirations, Demos has established a Centre for the Analysis of Social Media, a research centre dedicated to "social media science" that aims to explore the "datafication' of social life" and "see society-in-motion" through the new "digital commons" of big data:

To cope with the new kinds of data that exist, we need to use new big data techniques that can cope with them: computer systems to marshal the deluges of data, algorithms to shape and mould the data as we want and ways of visualising the data to turn complexity into sense. (Miller 2014: n.p.)

Underlying its commitment to both "postliberalism" and "social media science" is a belief that the behaviour of citizens - both individually and conceived as a massive digital commons - can be mined, analysed and predicted through data in order to make it possible to develop new policy ideas or governing solutions. It is on the basis of such citizen data, increasingly gathered through big data and social media methods, that Demos seeks to reimagine the public sector. The Innovation Unit and NESTA share many of its ideas and there is a flow of staff, publications and events between them.

The Innovation Unit describes itself as a "social enterprise" that is "committed to using the power of innovation to solve social challenges." The strapline on its website reads "Transforming public services" and its work in probation, schools and the NHS is clustered around themes of "public service design" and "co-production" (Innovation Unit 2014). Originating within the New Labour government's department for education and skills in 2002, the Innovation Unit was made into an independent social enterprise in 2006 to focus on innovative public services. Amongst its key ideas is that public services can best be reformed through the participation of new kinds of catalysts and brokers of ideas and relationships. In a key Innovation Unit publication, Honest Brokers: brokering innovation in public services, Horne (2008: 20), describes these as "innovation intermediaries." As Horne acknowledges, the model of innovation intermediaries is imported into public services from the science parks, business incubators and technology transfer companies associated with R\&D in the high technology sector. The blurb on the pamphlet asks "Where is the Silicon valley for public services in Britain?" Innovation intermediaries, he argues, can disrupt the monopoly hold of existing institutions by brokering new types of specialist knowledge, and brokering relationships between organisations "to create the right partnerships for innovative ideas to grow" (Horne, 2008: 28). Honest brokers mediate between public service providers and innovative companies to construct "innovation-rich sectors" that are "highly networked," and that work by "collaborating and recombining old ideas from diverse sources to create new ideas" (Horne, 2008: 30). The innovation intermediary represents a 
Williamson, B. 2014 forthcoming. Knowing public services: Cross sector intermediaries and algorithmic governance in public sector reform. Public Policy \& Administration.

hybrid organisational form that draws its power from a combination of high tech R\&D, political campaigning, media production, and community activism. The Innovation Unit carries out contract consultancy with commercial sector organisations, notably the technology companies Cisco Systems and Promethean. The Innovation Unit has self-published reports focusing on high-tech "innovation ecosystems" in public services ( "D\&R" processes of public sector innovation (Bentley \& Gillinson 2007), "people-powered health" and other forms of coproduction in the design and delivery of services (Innovation Unit 2013), often in collaboration with Demos and NESTA.

NESTA was established as a public body in 1998, to promote talent, creativity and innovation in science, technology and the arts, with an $£ 80 \mathrm{~m}$ endowment from the National Lottery, but otherwise it was independent of UK government. In 2012 NESTA formally became a charity rather than a public body, and was rebranded "Nesta" (for consistency I refer to NESTA throughout) under the leadership of former Demos founder Geoff Mulgan. In 2013 NESTA was closely involved in the establishment of a network of "evidence centres for social policy," specialist centres set up by the government Cabinet Office and Treasury to produce and disseminate research evidence of "what works" in major policy areas in order to inform services that "deliver the best outcomes for citizens" (HM Government 2013). In 2014 NESTA became part of a joint venture with the Behavioural Insights Team, a for-profit spinout from the UK government Cabinet Office dedicated to exploring how behavioural economics and psychological research on behaviour change can inform policies to "nudge" how citizens act.

NESTA defies simple categorisation. Among its various roles, NESTA supports "innovation systems" in all sectors, and acts as a source of both original research and policy work in the field of innovation. It runs panel discussions, seminars, lectures and networking events bringing together academics, financiers, inventors, public service providers and corporates. Its priorities include supporting innovation in the voluntary and public sectors and "digital R\&D". NESTA has published reports promoting "co-production" in health and social care (NESTA 2012a), "user-led design methods" and "design thinking" in public services (Mulgan 2014), innovative digital methods and new computational tools, web analytics, and big data in public sector reform (NESTA 2013). It performs both a conventional think tank role, in its production of policy documents, and a more experimental R\&D role as a laboratory for trying out new and innovative ideas in public services. Indicatively, its "public services innovation lab" focuses on "investigating how public services could meet the major social challenges in a time of falling budgets, looking at how techniques such as co-production and digital platforms could help generate new approaches" (NESTA, 2012b). In 2013, NESTA predicted that public and social policy in the future would emerge from new sites of governance that it imagined as "social science parks" and the "public policy lab" instead of from large central state bureaucracies. 
Williamson, B. 2014 forthcoming. Knowing public services: Cross sector intermediaries and algorithmic governance in public sector reform. Public Policy \& Administration.

The policy lab, of which its public services innovations lab is clearly a working model, is defined as "not so much a think tank but an experimental workshop that prototypes new forms of public service delivery" by working across "the public, private and social enterprise sectors to create socially useful and usable ideas" (NESTA 2013).

I collectively term these think tanks and cross-sectoral organisations "innovation intermediaries," to adopt Innovation Unit terminology, but their organisational format, style of work, and position in relation to public sector governance requires unpacking. They form a loose hybrid of the think tank, the social enterprise, and the charitable organisation, merged with aspects of the digital R\&D lab (all of which are themselves contested, elastic and emergent organisational forms). Relatively little research has been done specifically on such organisations in the UK, though there is a growing body of relevant political science studies of think tanks (Pautz, 2012), research on the contingent and hybrid nature of third sector organisations (Alcock \& Kendall, 2011), and studies of the contested discursive construction of social enterprise (Teasdale, 2012).

Some innovative think tank studies can help to conceptualise Demos, NESTA and the Innovation Unit. Medvetz (2012: 213-14) has analysed political think tanks sociologically as a hybrid and semi-structured organisational form "situated at the nexus of the political, academic, economic and media fields." By combining and balancing elements and institutional resources from each of these fields, including political know-how, the language of social science, media access, journalistic writing, and the techniques of activism, public relations and marketing, the power of think tanks "lies in their ability to claim for themselves a kind of mediating role" and "to establish a mixture of resources captured from other fields" (Medvetz 2012: 178). Wedel (2009) has similarly argued that in an increasingly flexible or "flexed" political climate, a new breed of political influencers has become prominent. These are "flexians" who inhabit "hybrid habitats," craft overlapping roles across the public and private sectors, and multiply their influences through "flex nets" and "multiplex" ties. Acting as catalysts, brokers, and fixers who construct new ideas through processes that are networked, bottom-up and interactive rather than elite and top down, think tanks like Demos deploy a "certain kind of intellectual attitude," that of the "mediator," that is now increasingly "available" for intellectuals and knowledge workers (Osborne, 2004: 431). The figure of the mediator is always "in the middle of things," acting as a propellant of new "vehicular ideas" and brokering alignments of interest between different constituencies. Mediators must act as "message-intensive" suppliers of "innovative political ideas" and informational "political commodities" that can capture the attention of politicians, the mass media and the public, and become powerful "impartational hubs" and "nodal statement disseminators" in "the information networks" through which contemporary political ideas and brands must now flow 
Williamson, B. 2014 forthcoming. Knowing public services: Cross sector intermediaries and algorithmic governance in public sector reform. Public Policy \& Administration.

(Arnoldi, 2007: 60). Mediators are the living embodiment of intermediaries like NESTA, Demos and the Innovation Unit, and products such as pamphlets, websites, policy briefing papers, press guides, and self-credentialed publications are their material forms.

It is important to note the political significance to these organisations of computer technologies and the potential of new forms of human-computer interaction for the governance of public services. Technological forms such as software systems, open source, and networks function for them not merely as channels for imparting and disseminating ideas. They are also emblematic of current intellectual and political preoccupations that take technologies to be templates or models of possible forms of governance. There are significant parallels between technological forms and political thought (Osborne \& Rose, 1999). According to Barry (2001: 14), this is an era in which feedback, interactivity, and the form of the network are increasingly viewed as important features of public service, "criss-crossing the distinction between the technical and the social," particularly, he adds, for think tanks of the "radical centre" including Demos that have sought to model public services on technological forms. Interactivity is important because it was "invented" in information and communication theory as a way of explaining how humans and machines function symmetrically through feedback loops as part of interacting systems (Barry, 2001). In more recent accounts of human-computer interaction there has been a greater interweaving and "synergistic combination" of human and machinic intelligence (Thrift, 2005: 183). "Machine learning" is the term to describe "intelligent" software systems that utilises statistical models from users' data to anticipate or even predict individuals' actions, behaviours and attitudes (Mackenzie 2013). The additional significance of interactivity, Barry (2001: 135) explains, is political, for in contemporary advanced liberalism the task of public authorities is not to direct or provide for the citizen but to establish conditions in which the citizen might become a more active, autonomous and responsible agent. Interactive technologies are expected to produce active citizens, revitalise democracy and reinvent the ideal of active political citizenship itself. More than just a technological form, interactivity has come to be a dominant model for the production of new kinds of citizens. Ideals about emerging forms of human-computer interaction, including the anticipatory and predictive potential of machine learning algorithms, have become the basis for the reimagining of public services, and as a model for new techniques of governing.

The "innovation intermediaries" of Demos, NESTA and the Innovation Unit can be understood as occupying a new institutional niche in British political life, although their actual influence in governance is debatable, like that of think tanks in general (Pautz, 2012). Rather than trying to define, classify or typologise them, or to locate them in a definite political or sectoral position or field, it is preferable to view them as a flexible and hybrid network and as cohabitees of a new kind of interstitial space that is in-between the think tank, the social enterprise, the digital $R \& D$ lab, the 
Williamson, B. 2014 forthcoming. Knowing public services: Cross sector intermediaries and algorithmic governance in public sector reform. Public Policy \& Administration.

public body and the not-for-profit sector. The interstitial organisations and mediators who embody these activities constantly interact among intellectual, bureaucratic, technological and media networks, resources, products and practices, re-assembling them into unique packages that can be branded, marketed, promoted and reinserted anew into public sector debate and into proposals for new techniques of governing. In what follows, I focus on reports, pamphlets and web products produced by these organisations as material techniques of such practices. Their printed and virtual media can be understood as material techniques that juxtapose ideas from a variety of political, social scientific and digital contexts in one place in order to stabilise them as explanations and arguments that are intended to influence policy decisions (Williamson 2014). The interactive style of this new kind of work is, then, the ideal intellectual attitude for the cross-sectoral intermediaries that are now increasingly catalysing, brokering, imparting and disseminating innovative political ideas about public sector reform and governance through techniques of humancomputer interaction. In the next two sections, I now examine the distinctive discourses of co-production and personalisation, and then algorithmic governance, before discussing how these combine as a model for a future of knowing public services in which citizens are to be governed and shaped.

\section{Co-producing personalisation}

This section traces the development of ideas of co-production, personalisation and participation in texts produced by Demos, NESTA and the Innovation Unit in order to trace the formation of knowing public services as a new model for governing the public sector. These discourses constitute a set of approaches to the governing of individuals, where governing is to be understood as the active shaping of citizens' capabilities and capacities to act (Rose 1999).

In 2004, Charles Leadbeater and Paul Miller published the Demos pamphlet The ProAm Revolution: How enthusiasts are changing our economy and society. The simple argument was that the dominant social trend in the twentieth century was for things to be done by expert professionals and by large hierarchical organisations. At the beginning of the twenty-first century, however, they argued that "a new breed of amateur has emerged: the Pro-Am, amateurs who work to professional standards":

The Pro-Ams are knowledgeable, educated, committed and networked, by new technology. ... Pro-Ams are creating new, distributed organisational models that will be innovative, adaptive and low-cost. (Leadbeater \& Miller, 2004: 12).

Pro-Ams are an emerging social hybrid whose activities cannot be divided up into binary opposites of work and leisure, consumption and production, or professional and amateur. Drawing specifically on ideas about "group forming network technologies" from the internet theorist Howard Rheingold, Leadbeater and Miller (2004: 45) argue that Pro-Ams are "creatures of digital technologies" who use specialist websites to locate information, advice, knowledge and contacts. They also 
Williamson, B. 2014 forthcoming. Knowing public services: Cross sector intermediaries and algorithmic governance in public sector reform. Public Policy \& Administration.

claim that Pro-Ams are important originators of "disruptive" and "radical" technological innovations, and specific parallels are drawn between Pro-Ams and the model of "open, mass innovation" that has been embraced as a source of revenue generation in the videogames industry. "Pro-Am communities," Leadbeater and Miller (2004: 67) argue, "are the new R\&D labs of the digital economy."

It is especially significant that they see Pro-Ams as "vital to service innovation," and argue that "harnessing Pro-Am service innovators will be vital to the future of public services, especially in health, social care and education" (Leadbeater \& Miller, 2004: 53). They envisage "a kind of guerrilla army" of Pro-Am "advisers, helpers and innovators" in all public institutions, "from public libraries to the BBC, schools and hospitals" (Leadbeater \& Miller, 2004: 59), all interacting in service innovation through the social networks and collaboration technologies of the internet. In their account, the internet has allowed formerly expert knowledges to escape formal professional control. The Pro-Am is perhaps the prototypical interactive citizen whose participation in public service provision is modelled on the interactivity of software systems (an idea explored further below).

In conclusion, Leadbeater and Miller (2004: 71) state that the "Pro-Ams will bring new forms of organisation into life, which are collaborative, networked, light on structure and largely self-regulating." This vision is re-articulated in the NESTA model of "public services inside out," where users are repositioned as service coproducers and public service agencies become "catalysts and facilitators of change rather than central providers of services," thus "blurring the distinction between professionals and recipients, and between producers and consumers of services" (Boyle, Slay \& Stephens 2010: 19, 15). A sister publication from NESTA focuses on taking co-production methods into the mainstream of public service design and delivery, contributing to "a new kind of public sector based on relationships rather than departmental structures" (Boyle, Coote, Sherwood \& Slay 2010) Although "ProAm power" and debates about consumers and producers as co-producers are not entirely symmetrical, they combine genealogically in the production of a discourse in which citizens are positioned with new powers to participate in public service design.

The self-regulating, networked and interactive image of the citizen participating in the "Pro-Am revolution" is part of a wide and ambitious Demos project to "personalise" public services in the UK. Introduced into public service discourse around 2004, Needham (2011: 4) argues that "personalisation was a term that helped to summarise all that was wrong with existing public services and what could be done to improve them." Leadbeater, again, has advocated personalisation in a series of pamphlets variously focusing on public services including education, health, and social care published both by Demos and the Innovation Unit. In Personalisation through participation: A new script for public services, Leadbeater (2004: 16) emphasises 
Williamson, B. 2014 forthcoming. Knowing public services: Cross sector intermediaries and algorithmic governance in public sector reform. Public Policy \& Administration.

"bottom-up, mass social innovation, enabled by the state," with public service users positioned as "co-producers," "active participants" and "self-managers" who contribute to "self-organizing" solutions. Personalisation implies "the public good emerging from within society, in part, through the way that public policy shapes millions of individual decisions" (Leadbeater, 2004: 23).

Elsewhere, Demos researchers define a personalised approach to public services as mobilizing the person involved as a participant in its production. The ideal of selfdirected and personalised public services is at the centre of a new "politics of participation":

Government's role is to shape freedom: getting people to exercise choice in a collectively responsible way and so participate in creating public goods. Self-directed services provide a working model for just that: how to shape people's choices to promote socially beneficial, collective outcomes. (Leadbeater, Bartlett \& Gallagher, 2008: 79)

These authors claim that the personalisation and co-production of public services changes the role of professionals and users. In co-produced services, professionals such as teachers, social workers and doctors retain a critical overview of service quality and outcomes, but they are repositioned as "advisers, counsellors and brokers, guiding people to make better choices for themselves" (Leadbeater, Bartlett \& Gallagher, 2008: 11). Moreover, the shift to co-produced services brings in new sources of information, knowledge and expertise. Instead of relying on the skills and knowledge of managers and professionals as gatekeepers and administrators of services, participative approaches bring in "more detailed knowledge from users, their families, peers and friends, about what is important and how it could be done" (Leadbeater, Bartlett \& Gallagher 2008: 12).

The Innovation Unit and NESTA have contributed to imagining the new landscape of co-produced and personalised public services in a series of projects and reports under the collective title "Radical Efficiency." Described as a "system change for central government," radical efficiency is based on principles of "partnership with users"; leadership by amateurs; citizen engagement in public policymaking; and the "liberation" of local autonomy and communities (Gillinson, Horne \& Baeck, 2010: 2$3)$. In a report prepared in association with the public services innovation lab at NESTA, Innovation Unit researchers Gillinson, Horne \& Baeck (2010: 9-10) argue that radical efficiency is about a new relationship with users as partners "in the collaborative design and delivery of services." Radical efficiency also puts humancomputer interaction at the centre of the design of services. The model repositions public service "users as co-producers" who put their personal and collective experiential assets to work to catalyse change, partly through mobilising the algorithmic processes of data mining. The report advocates a range of both state and non-state organisations being "truly connected to citizens and a shared aspiration for UK society" (Gillinson, Horne \& Baeck, 2010: 57). 
Williamson, B. 2014 forthcoming. Knowing public services: Cross sector intermediaries and algorithmic governance in public sector reform. Public Policy \& Administration.

This section has sought to show through analysing key texts how NESTA, Demos and the Innovation Unit have contributed collectively to the production of a new model of public service design and delivery, through which individuals are to be governed and empowered as active co-producers of personalised services. They imagine public services to be governed by networks of new kinds of intermediary and brokering organisations (modelled in part on the digital R\&D sector as well as on think tank culture) rather than state bureaucracies, and they imagine these organisations to be personalising services through a mixture of co-production and digital data collection and analysis. In an analysis of this policy context, Meijer (2012) has argued that just as "user-generated content" has become the staple of social media on the worldwide web, these practices represent a model for a new kind of "user-generated state" promoted by technology enthusiasts working in public service reform:

\footnotetext{
The dominant, consumerist ideas about technology in government are being challenged by a coalition of advocates of co-production and social media enthusiasts. Ideas about coproduction developed in the administrative sciences match well with ideas about coproduction as they have been developed in the internet community and by technology gurus. One of the core assumptions of Web 2.0 is that users generate content. Content is no longer produced and provided by the public service provider but rather being created-i.e., coproduced-in networks and communities.
}

This shift from a mass, centralised form of provision to more networked, coproduced and personalised provision is dependent on moving power away from professionals and towards users, a two-way interaction that might involve diverse intermediaries in "shaping relations between citizens and government" (Meijer, 2012).

At the crux of the new model of public services and governing imagined by Demos, the Innovation Unit and NESTA is the issue of interactivity-especially humancomputer interactivity. The feedback loops of co-produced and personalised public services imagined in these texts, based on the model of user-generated content on the web, promote a citizen subject who is supposed to be active, responsible, and autonomous enough to function as part of an interacting system, where service providers and service users are enclosed in perpetual cycles of interactivity. Barry (2001: 148) argues that in an "interactive model" of political life (rather than the directive model of disciplinary government), intensive interaction with the public and the political imagination of ordinary citizens is expected to "intensify feedback between government and the governed and to minimise the possibilities for unexpected political controversies and conflicts." Barry (2001: 251 n.111) refers to a Demos article entitled "Networks for an open society" by Geoff Mulgan as evidence for the contemporary political currency of an interactive model of politics. In the interactive model the authority of professional expertise is concealed in order to maximise the possibilities for interaction, and the experiential expertise of the 
Williamson, B. 2014 forthcoming. Knowing public services: Cross sector intermediaries and algorithmic governance in public sector reform. Public Policy \& Administration.

ordinary citizen is to be worked with rather than contradicted, instructed or directed. The explicit argument made in Demos documents about personalisation that government's role is "to shape freedom" echoes Rose's (1999) argument that contemporary liberal governance depends on a certain shaping of autonomygoverning as acting upon action - and the fostering of the freedom necessary to enhance the self-governing capacities of the citizen. The interactive model of coproduction and personalisation proposed by Demos, NESTA and the Innovation Unit is prototypical of new approaches to governing which seek to work through and act upon the active capacities and capabilities of the individual through techniques modelled on technological forms. However, these aims are increasingly being augmented with claims about new forms of human-computer interaction utilising sophisticated data mining algorithms and machine learning methods with the additional capacity to automate the personalisation of public services.

\section{Algorithmic governance}

In recent documents Demos, Innovation Unit and NESTA researchers have begun to promote databases, data analytics, adaptive software, and other emerging forms of human-computer interaction facilitated by new algorithmic data-processing techniques and "computation power" (NESTA, 2013) as a solution to public service design and delivery. These texts, which are examined in this section, construct algorithmic practices of data collection, analysis and machine learning as interactive relays between service provider and service user, or between governing authority and the governed. This is what might be termed an aspiration to new forms of algorithmic governance in public services, within which services users and algorithms are interwoven as co-producers of services.

In the Demos pamphlet The Civic Long Tail, Leadbeater (2011) argues that social media and web 2.0 are remaking the relationship between government and citizens. According to the interpretation offered in the pamphlet, the widespread use of social media is creating huge amounts of information and data sources that could provide new sources of economic and social innovation, with particular potential benefits for public services. He states that as a massive number of miniscule interactions and transactions are amassed into enormous databases, a potentially rich mine of information becomes available for governments who want to connect, or to control, what citizens do, and to shift their sentiments, interests and demands:

Even if social media does not become a platform for overtly political activity, it is already changing how citizens expect to be treated and so what they expect of government. As people are being inducted into a more open, participative and expressive culture in their everyday lives, they are bound to carry those expectations into their interactions with government. (Leadbeater, 2011: 9)

If government can act effectively to harness the tools of social media and the data it produces, Leadbeater (2011) predicts the possibility of new forms of "emergent 
Williamson, B. 2014 forthcoming. Knowing public services: Cross sector intermediaries and algorithmic governance in public sector reform. Public Policy \& Administration.

democracy," "collaborative and conversational forms of governance," and "democratic systems that can operate at scale and yet be fluid, adaptive and engaging when needed." In The Civic Long Tail new technological forms and their underlying algorithmic processes are paralleled by the potential for new political forms. Techniques of data mining, cloud computing, the social web, intelligent systems, and the ideal of the "hopeful web" are interwoven with the political imaginary of a smarter, more open, and more intelligent form of "Government 2.0." Leadbeater (2011: 18) describes a system of "government by algorithm" that uses "systems to mine and analyse data, to make automated decisions about allocating resources," so that "Government departments, service delivery chains and entire cities could be run by pervasive, invisible systems." The Civic Long Tail aligns and juxtaposes the "conversational governance" of co-production and personalisation with government by algorithm to create "more effective and intelligent public systems, based in part on the analysis of 'big data' combined with more adaptive and capable communities, able to use the data to solve problems they face" (Leadbeater, 2011: 18). The text clearly juxtaposes the person-centred emphasis of the personalisation and co-production discourses with the possibilities of algorithmic data processing to further enhance and improve the information and knowledge of people that are required to govern.

This new algorithmic relationship between governing authority and the governed crucially depends on digital data - or "big data." In a follow-up pamphlet, The Data Dialogue, Demos researcher Bartlett (2012) argues that there are two main types of big data that are relevant to public service debates. As we shop and subscribe on and offline, we provide personal information, which directly identifies us: bank details, telephone number, home address and so on. As we spend more time connected to the internet, we create more behavioural data: information that may be generated by individuals but which is anonymised and aggregated when stored and analysed. The pamphlet presents a number of "mutual benefits" that can come from sharing personal and behavioural data online, including the creation of new "services and applications that are more tailored to users' needs" (Bartlett 2012: 20) A more personalised, intelligent and knowing form of public services provision powered by algorithmic procedures is anticipated by the pamphlet. Likewise, in The Data Dividend, Demos researchers Wind-Cowie and Lekhi (2012: 63) argue that big data "should be viewed as a transformative agent that has the potential to revitalise, reinvigorate and renew public services." The platforms that citizens already use to access public services, they argue, should be equipped with the most up to date analytics software in order to generate the kind of everyday data about citizens that companies produce about customers. These everyday data are taken to be essential to the design of more personalised public services based on public users' personal data as well as on aggregated behavioural data. The transformation of public services can be achieved through the same process that has driven the development of open source technologies. Wind-Cowie and Lekhi (2012: 10) argue: 
Williamson, B. 2014 forthcoming. Knowing public services: Cross sector intermediaries and algorithmic governance in public sector reform. Public Policy \& Administration.

The dynamics of service improvement through data use draw equally from technological and democratic sources. From the technological perspective, identifying problems in service delivery can be seen as a similar process to debugging software.

The open source software approach to finessing computer code is paralleled by "the democratisation of public services" as it "provides an opportunity for heightened and positive engagement and co-production." Such approaches presuppose that algorithmic analytics software and data now offer potential for more democratic and participatory forms of public service. Such technologies offer the potential for the automatic production of personalised public services.

These Demos publications demonstrate how a political concern with the interactivity of software, algorithmic processes and big data in everyday life is now being used as the template for a thoroughgoing reimagining of public participation in the reform of public services. Service users are being actively solicited as experiential agents whose general lay expertise is to be aggregated with big data in order to generate new tailored or personalised public services. The imaginative possibilities for more personalised, co-produced and knowing public services associated with the algorithmic processes of software are continued in the public services lab at NESTA. The idea of co-production through software runs throughout a series of NESTA projects collected under the banner "Digital Public Services," as documented in a collection of essays entitled Reboot Britain: How the promise of our new digital age can tackle the challenges we face as a country (Coyle, 2009). This publication is significant because it identifies three common themes: first, the promise of new technologies (for more efficient services, greater entrepreneurial opportunities, and the "democratic possibility of connected participation"); second, the need for new forms of devolved governance in public services; and third, the "need to engage people widely and directly in delivering solutions," especially through "flat networks" (Coyle, 2009: np). Again, the text positions algorithmic processes as a relay between governing authority and the governable citizen.

Its recommendations are taken up in subsequent NESTA texts. Early in 2013, NESTA produced a set of annual predictions that reads as a catalogue of emerging algorithmic techniques paralleled by new ideas about the social and political order. The list includes:

- the growth of "digital public services" as "user-centred design" methods, social media and access to "open research databases" are combined and brought into public services;

- a new trend in "civic apps" - citizen-oriented digital services based on open data which add value to public services;

- the emergence of adaptive technologies which use data, algorithmic analytics and feedback mechanisms to adapt and personalise services;

- the institutionalisation of "crowdsourcing" as a "democratic" method for solving social problems facilitated by "computation power" and "big data";

- the growth of a "sharing economy" based on "collaborative consumption" using peer-to-peer technology services. (NESTA 2013) 
The predictions depict a near-future scenario for a public sector constituted by "digital public services" and embedded in new kinds of "computation power": algorithmically-powered tools, apps and devices, and analytics software that are capable of sorting through big data sets and producing adaptive personalised solutions autonomously of human intervention. This potential to facilitate better interaction between politics and social media is what underlies the commitment of Demos to engaging with the big data generated by the "digital commons" (Miller 2014) and to eliciting the citizen's "digital voice" for a "postliberal future"(Goodhart 2014). The new Centre for the Analysis of Social Media at Demos utilises "taught algorithms" to understand citizens' behaviour and attitudes, and then to use that data to "predict how they act" in the future (Miller 2014). These predictive data can then be used as the basis for policy decision-making. As Mackenzie (2013: 399) argues in a recent article on machine learning and predictive analytics, "programmers construct models that predict what people will do" through "transforming data on events, actions, behaviours, beliefs and desires" into probabilistic predictions of the future that can be used to decide on action to be taken in the present. In the context of digital governance, this would involve utilising taught algorithms, recursive feedback models, and analytics software that can anticipate citizens' actions and behaviour based on sources of big data in order to identify appropriate public service provision. Algorithms that can be taught to anticipate and predict how people act, or machine learning, have been positioned as a major component of the new techniques of governing promoted by these think tankers and intermediaries.

Governing means acting upon action-shaping the way people act. The future envisaged by Demos, NESTA and Innovation Unit researchers puts machine learning processes into public service design. In these future possibilities, a new style of knowing public services is being invented, in which data analytics methods are to be used to trace and sort the data produced by citizens in order to anticipate their future lives and so personalise services. The products of these techniques are automated, anticipatory and algorithmic public services in which provision is allocated without significant human involvement, judgement tor decision-making. Governing in this scenario means taught algorithms acting upon the action of citizens. The service user constructed by anticipatory public services interacts distantly with algorithmic machine learning processes by providing personal and behavioural data that can be analysed to generate tailored provision. If installed in public services, these technologies would govern through automated, predictive and anticipatory means.

\section{Interactive citizenship}

In this brief discussion, I want to speculate on the possible implications of machine learning and the automated, anticipatory and algorithmic forms of governance it 
Williamson, B. 2014 forthcoming. Knowing public services: Cross sector intermediaries and algorithmic governance in public sector reform. Public Policy \& Administration.

introduces in public services for the identity formation of individual citizens and service users. In important analysis of government databases, Ruppert (2013) describes how various database technologies and sources of data are now being deployed in public services. These include vast joined-up databases and electronic management information systems that combine data on individuals, such as biographical information, data on evaluations, assessments, interventions, and judgements compiled across multiple government sites. Ruppert (2013) shows how specific software tools designed to facilitate public services have been designed for "data-driven decision-making," joining up data from multiple contexts and datasets in order to "identify" and make the individual "visible" as the potential object or target of highly individualised governing intervention. However, these government databases do not merely represent the individual. Instead, as they continually join together different pieces of data, they constantly remake the identity of the individual, anticipate likely future behaviours and requirements, and continually recalculate decisions about the best lines of intervention. The individual is a composite enactment made up by software out of data rather than a fixed and stable identity. As she argues, "such software systems or 'algorithm machines' do not merely implement a policy or programme but are generative of both their subjects of governing and modes of intervention" (Ruppert 2013: n.p.). This "database way of thinking" about governing, or "database government," seeks to intervene, through 'personalised packages of public services,' in 'both who people are and who they are possibly becoming' (Ruppert 2012: 128, 130).

The techniques of algorithmic governance promoted by Demos, NESTA and the Innovation Unit actively reimagine, reconstitute and "make up" the citizen with new kinds of capacities, competencies and forms of conduct. The citizen imagined by these organizations is to be shaped, empowered and activated as a participative co-producer of personalised public services, whose data from such forms of participation can then be collected and calculated in a constant feedback loop in order to further automate and tailor future services through anticipatory algorithms. Ultimately, the activation of the citizen is akin to what Cheney-Lippold (2011: 165) has termed a "new algorithmic identity," an identity formation that "works through mathematical algorithms to infer categories of identity on otherwise anonymous beings." Such an identity is not constituted by actual conduct but constructed out of quantifiable digital input and output data. In this sense, the database-driven and algorithmic forms of governance in public services proposed by Demos, Nesta and the Innovation Unit would not just work by identifying and categorising individuals, but would be dynamically co-constitutive of new kinds of persons for futures yet to come. The interactive citizen "made up" by these intermediary organisations is not just a recipient of new personalised public services, but algorithmically interwoven with such services in a constant automated feedback loop of automated data collection, analysis, and anticipation in order to predict, automate and personalise future service provision. The conduct of the citizen is to 
Williamson, B. 2014 forthcoming. Knowing public services: Cross sector intermediaries and algorithmic governance in public sector reform. Public Policy \& Administration.

become the target of personalised public services and decision making that is in part delegated to the algorithmic power of database software.

\section{Conclusion}

This article has traced the participation in public sector reform debates of the crosssectoral innovation intermediaries Demos, NESTA, and the Innovation Unit, focusing particularly on their reimagining of the public services as a process of human-computer interaction. These organisations act as mediators of new political ideas that are intended to change the way people think. Their ideas are embodied in the production of reports, pamphlets and websites that act as relays and material transmitters of new ways of thinking about public service provision and organisation. Their power lies in their capacity to establish a blurry combination of resources captured from other fields and sectors, and to mediate these resources into unique and marketable policy packages, political commodities, and practical projects. Through such combinations, they generate a discourse which seems to make certain ideas thinkable, intelligible, and practicable.

The resources produced by Demos, NESTA and the Innovation Unit create parallels between contemporary technological forms and a vision of a smarter kind of public service provision based on a particular form of human-computer interaction in which public services are to be co-produced by citizens interacting with algorithms. The public sector imagined by these organisations is adaptive, interactive, and personalised, and is intended to shape and activate a new kind of interactive citizen subject, a subject who would participate interactively in the production of personalised services through feedback loops facilitated by the algorithmic powers of software systems, data analytics, and predictive technologies. This is an extreme form of human-computer interaction in digital governance utilising "zero-touch technologies" that can act autonomously of human oversight (Margetts \& Dunleavy 2013) in order to automate and digitize the interaction between government and citizen. Algorithmic governance functions through collecting, collating and calculating the data of citizens in order to predict their probable future needs, and by automating the process of personalisation. This process of automated, anticipatory, and algorithmic governance in public services actively intervenes in people's lives, seeking to activate their capacities and capabilities for responsible self-governing. In this sense, governance of public services is not merely being distributed to crosssector actors such as think tanks, policy labs and innovation intermediaries, but dispersed among a wider set of technical actors including databases, algorithms, and software that are programmed with the capacity to act autonomously of human oversight. In knowing public services, the governing of citizens - the shaping of how they act and conduct themselves - is to be delegated to the power of the algorithm. 
Williamson, B. 2014 forthcoming. Knowing public services: Cross sector intermediaries and algorithmic governance in public sector reform. Public Policy \& Administration.

\section{References}

Alcock, P \& Kendall, J (2011) Constituting the Third Sector: Processes of Decontestation and Contention under the UK Labour Governments in England. Voluntas 22: 450-469

Arnoldi, J (2007) Informational Ideas. Thesis Eleven 89: 58-73

Barry, A (2001) Political Machines: Governing a technological society. London: Athlone Press.

Bartlett, J (2012) The Data Dialogue. London: Demos.

Bentham, J (2006) The IPPR and demos: Think tanks of the new social democracy. The Political Quarterly 77, no. 2: 166-74.

Bentley, T \& Gillinson, S (2007) A DER System for Education. London: Innovation Unit.

Boyle, D, Coote, A, Sherwood, C \& Slay, J (2010) Right here, right now: Taking co-production into the mainstream. London: NESTA.

Boyle, D, Slay, J \& Stephens, L (2010) Public services inside out: Putting co-production into practice. London: NESTA.

Brandsen, T \& Pestoff, V (2006) Co-production, the third sector and public service delivery. Public Management Review 8, no. 4: 493-501.

Cheney-Lippold, J (2007) A New Algorithmic Identity: Soft Biopolitics and the Modulation of Control. Theory, Culture \& Society 28: 164-181.

Coyle, D (ed) (2009) Reboot Britain: How the promise of our new digital age can tackle the challenges we face as a country. London: NESTA.

Davies, W (2012) The Emerging Neocommunitarianism. The Political Quarterly 83, no. 4: 767-776.

Fenwick, T, Mangez, E \& Ozga, J (eds) (2014) Governing Knowledge: Comparison, Knowledge-Based Technologies and Expertise in the Regulation of Education. London: Routledge

Gillinson, S, Horne, M \& Baeck, P (2010) Radical Efficiency: Different, better, lower cost public services. London: Innovation Unit/NESTA.

Goodhart, D (2013) Preface. In R Scott \& D Goodhart (eds) Twenty Years of Ideas. London: Demos

Goodhart, D (2014) A postliberal future? Demos Quarterly, issue 1, Winter 2013/14. Available online: http://quarterly.demos.co.uk/article/issue-1/a-postliberal-future/ (accessed 11 February 2014)

Grek, S \& Ozga, J (2010) Re-inventing Public Education: The new role of knowledge in education policy making. Public Policy and Administration 25: 271-288.

Hannon, V, Patton, A \& Temperley, J (2011) Developing an Innovation Ecosystem for Education: White paper. San Jose, CA: Cisco Systems.

HM Government (2013) What Works: evidence centres for social policy. London: Cabinet Office.

Horne, M (2008) Honest brokers: Brokering innovation in public services London: Innovation Unit.

Innovation Unit (2013) Guide to People Powered Health. Innovation Unit website. Available online: http://www.innovationunit.org/sites/default/files/Guide $\% 20$ to $\% 20$ People $\% 20$ Powered $\% 20$ Health_0.pdf (accessed 11 February 2014)

Innovation Unit (2014) Our ideas on... Innovation Unit website. Available online: http://www.innovationunit.org/knowledge/our-ideas (accessed 11 February 2014)

Kitchin, R \& Dodge, M (2011) Code/Space: Software and Everyday Life. London: MIT Press. 
Williamson, B. 2014 forthcoming. Knowing public services: Cross sector intermediaries and algorithmic governance in public sector reform. Public Policy \& Administration.

Leadbeater, C \& Miller, P (2004) The Pro-Am Revolution: How enthusiasts are changing our economy and society. London: Demos.

Leadbeater, C (2004) Personalisation through Participation: A new script for public services. London: Demos.

Leadbeater, C (2011) The Civic Long Tail. London: Demos.

Leadbeater, C, Bartlett, J \& Gallagher, N (2008) Making it Personal. London: Demos

Mackenzie, A (2013) Programming subjects in the regime of anticipation: Software studies and subjectivity. Subjectivity 6, no. 4: 391-405

MacMillan, J (2012) Making sense of the Big Society: perspectives from the third sector. Birmingham: Third Sector Research Centre.

Margetts, H \& Dunleavy, P (2013) The second wave of digital-era governance: a quasi-paradigm for government on the Web. Philosophical Transactions of The Royal Society A 371.

McCarthy, Miller \& Skidmore (2004) Network Logic. London: Demos.

Medvetz, T (2012) Think Tanks in America. London: University of Chicago Press.

Meijer, A (2012) Co-production in an Information Age: Individual and community engagement supported by new media. Voluntas. DOI 10.1007/s11266-012-9311-z

Milbourne, L \& Cushman, M (2013) From the Third Sector to the Big Society: How Changing UK Government Policies Have Eroded Third Sector Trust. Voluntas 24: 485-508.

Miller, C (2014) The promise of social media. Demos Quarterly, issue 1, Winter 2013/14. Available online: http://quarterly.demos.co.uk/article/issue-1/the-promise-of-social-media/ (accessed 11 February 2014)

Mulgan, G (2005) Reshaping the State and its Relationship with Citizens: the Short, Medium and Long-term Potential of ICT. In M. Castells \& G. Cardoso (eds). The Network Society from Knowledge to Policy. Washington, DC: Johns Hopkins Center for Transatlantic Relations

Mulgan, G (2006) Thinking in tanks: The changing ecology of political ideas. The Political Quarterly 77, no. 2: 147-55.

Mulgan, G (2014) Design in public and social innovation. NESTA website. Available online: http://www.nesta.org.uk/sites/default/files/design in public and social innovation.pdf (accessed 11 February 2014)

Mulgan, G \& Steinberg, T (2005) Wide Open: Open source methods and their future potential. London: Demos

Needham, C (2011) Personalising Public Services: Understanding the personalisation narrative. Bristol: Policy Press.

NESTA (2012a) People powered health: Co-Production Catalogue. London: NESTA.

NESTA (2012b) A brief history of NESTA. London: NESTA.

NESTA (2013) 13 predictions for 2013. NESTA website. Online:

http://www.NESTA.org.uk/news and features/13for2013 (accessed 7 February 2013).

Osborne, TSD (2004) On mediators: Intellectuals and the ideas trade in the knowledge society. Economy \& Society 33, no. 4: 430-47.

Osborne, TSD \& Rose, N (1999) Governing cities: Notes on the spatialisation of virtue. Environment \& Planning D: Society \& Space, 17: 737-760 
Williamson, B. 2014 forthcoming. Knowing public services: Cross sector intermediaries and algorithmic governance in public sector reform. Public Policy \& Administration.

Painter, C (2013) The UK Coalition government: Constructing public service reform narratives. Public Policy and Administration 28: 3-20.

Pautz, H (2011) Revisiting the think tank phenomenon. Public Policy $\mathcal{E}$ Administration 26: 419-435.

Pestoff, V, Osborne, SP \& Brandsen, T (2006) Patterns of co-production in public services. Public Management Review 8, no. 4: 591-595.

Rose, N (1999) Powers of Freedom: Reframing political thought. Cambridge: Cambridge University Press.

Ruppert, E (2012) The Governmental Topologies of Database Devices. Theory, Culture \& Society 29, no. 4-5: 116-136.

Ruppert E (2013) Not just another database: the transactions that enact young offenders. Computational Culture, issue 3. Available online: http://computationalculture.net/article/notjust-another-database-the-transactions-that-enact-young-offenders (accessed 11 February 2014)

Teasdale, S (2012) What's in a name? making sense of social enterprise discourse. Public Policy $\mathcal{E}$ Administration 27, no. 2: 99-119.

Thrift, N (2005) Knowing Capitalism. London: Sage.

Wedel, JR (2009) Shadow Elite: How the world's new power brokers undermine democracy, government and the free market. New York: Basic Books.

Williamson, B (2014) New governing experts in education: Self-learning software, policy labs, and transactional pedagogies. In T Fenwick, E Mangez \& J Ozga (eds) Governing Knowledge: Comparison, Knowledge-Based Technologies and Expertise in the Regulation of Education: 218-231. London: Routledge

Wind-Cowie, M \& Lekhi, R (2012) The Data Dividend. London: Demos. 